\title{
Aurelian ANGHELESCU
}

Corresponding author: Aurelian Anghelescu, E-mail: aurelian_anghelescu@yahoo.co.uk

\begin{abstract}
Winter-sport participation may be associated with a risk of injuries. The article provides a brief overview of the epidemiology of winter sports-related trauma, referring to common skiing and snowboarding injuries in professional athletes or inexperienced ones (amateurs), to determine injury patterns, crash circumstances, their pathological repercussions, and possible preventive interventions.Known risk factors for the occurrence of injuries are: lack of experience in snow-sports, suboptimal skill and technical level, poor physical fitness level, fatigue, risk-taking behavior, alcohol consumption, absence or rented and/ or faulty equipment and protective devices, high speed, ice on the slope, bad weather conditions and poor visibility, crowd on the track. This short exposure aims to educate younger (recreational) skiers and snowboarders to prevent traumatic injuries to the limbs and especially the catastrophic ones, resulting in central nervous system lesions, with devastating consequences for athletes, their families, and communities. The paper has a multidisciplinary addressability: it may be useful for general practitioners and young specialists in orthopedics, neurology, physical medicine \& rehabilitation, and kinetotherapy.
\end{abstract}

Key words: winter sports; snowboarding injuries; skiing injuries; bobsleigh; luge; skeleton; spinal cord injury; traumatic brain injury; injury prevention; physical disability,

\section{Introduction}

Being active in sports has many positive health effects, and provides many benefits to physical and mental health. The Latins had a famous proverb: "Mens sana in corpore sano / A sound mind in a healthy body".

Recreational or professional alpine skiing, snowboarding, luge, are increasing in popularity worldwide, enjoyed by million of participants of all ages and skill levels. In 2010 an estimated 11.5 million people in the United States participated in skiing, and 8.2 million engaged in snowboarding (1). Besides the beneficial health effects of an active life style, sport participation may be unfortunately associated with risk of injuries.

Sometimes devastating traumatic injuries can have dramatically consequences for the athletes, their families, and communities. Severe post traumatic neurological injuries can raise significant public health concern, and even may discourage participation in sport. Michael Schumacher's dramatic fate was an intensely covered topic in massmedia, five years ago.

\section{Material and method}

A systematic search of Pubmed Database focused on the above-mentioned keywords was conducted to identify relevant articles and systematic reviews published in English literature, reporting winter-sport related accidents.

This article is a short overview of the epidemiology of snow sport-related trauma, referring to the common skiing and snowboarding injuries in professional athletes or inexperienced (amateurs) tourists, to determine the injury patterns, crash circumstances, their pathological repercussions, and possible preventive interventions.

Known risk factors for the occurrence of injuries are lack of experience in snow-sports, technical errors, suboptimal technical level and poor physical fitness level, fatigue, risk-taking behavior, and alcohol consumption, presence of ice on the slope, bad weather conditions and poor visibility, crowd on the track, high speed, rented or faulty equipment or protective devices $(2,3,4)$.

Local mountaineers ironically and generically call a category of amateurs, inexperienced athletes, as "paltonari" (term derived from "palton", similar to the English word "paletot"), referring to their unfit 
mountain equipment and imprudent behavior. These inexperienced skiers and snowboarders are usually exuberant and defiant young persons, predisposed to alcohol consumption and risk-taking behavior with dramatic repercussions (severe limb fractures or catastrophic neurologic injuries).

Recent international literature reviews emphasize that the incidence of traumatic brain injury (TBI) and spinal cord injury (SCI) in winter sport activities are increasing, mainly in alpine skiing and snowboarding $(5,38)$. Although uncommon, fatal and severe nonfatal (but with dramatic debilitating sequels) brain and spine injuries can occur during winter-sports, and induce enormous financial burden to society. These accidents may happen at all levels of play, from youth to professional athletes $(6,7)$. In Canada, all winter sports injuries are responsible for significant health care burden, with estimates of $\$ 400$ million in direct and indirect annual health care costs (8).

Catastrophic spinal injuries in sports are rare but tragic events, and athletic competition has long been a known source of spinal cord injuries (SCIs). SCI is a rare but serious event and a major cause of morbidity and mortality for skiers and snowboarders. Approximately $8.7 \%$ of all new cases of SCIs in the United States are related to (general) sports activities; ice hockey, skiing and snowboarding are among the highest risk-spots for SCIs (7). Spine trauma is among the most devastating injuries in snow sports, comprising $1 \%$ to $17 \%$ of all injuries in skiers and snowboarders $(9,10)$. Different epidemiological studies emphasized that most SCIs occurred after intentional jumps, rather than collisions $(11,12)$.

In $13.4 \%$ patients, most commonly seen are "tandem injuries": a closed head injury and cervical spine trauma, with possible catastrophic repercussions (13). Safety helmets decrease the risk for and the severity of head injuries. Although helmets do not protect the spine, they certainly do not increase the risk of neck and cervical injuries $(14,15)$.

The common mechanism of SCI for all at-risk winter sports is represented by an axial compression force to the top of the head with the neck in neutral position of slightly flexed (7). The biomechanical dynamic proprieties of the head and spine, the force vector applied during impact, the intrinsic strength and anatomy of vertebral bodies and their surrounding spinal elements (16) concur to SCI. In neutral, vertical position, the average weight of human head is around 4.5 to $5 \mathrm{~kg}$ at rest. As the head is bending forward, its weigh increases from $13 \mathrm{~kg}$ (at $15^{\circ}$ ), to $20 \mathrm{~kg}\left(\right.$ at $\left.30^{\circ}\right), 24,5 \mathrm{~kg}\left(\right.$ at $\left.45^{\circ}\right), 30 \mathrm{~kg}$ (at $\left.60^{\circ}\right)(17)$. These biomechanical variable factors may explain a cervical SCI after an accidental fall on the ischial tuberosities.

Spinal injury patterns among snowboarders and skiers associated cervical spine trauma in 19.6\% cases vs. $10.9 \%$ of thoracic and $6 \%$ of lumbar injuries (13).

A systematic review of published literature (1980 2015) reporting the epidemiology of sport-related SCIs emphasized that the greatest majority of cervical SCIs were encountered in hockey and skiing, whereas in snowboarding over half of the spinal lesions were fond with predilection in the thoracic or lumbosacral levels (18). In snowboarders falling backward represent the mechanism of spine injury (typically in the fragile thoracolumbar junction), causing an axial load or a flexion-distraction moment $(11,19)$.

Lower trunk lesions (pelvis, hip, lumbar spine) are usually characteristic of snowboarders (20). Acrobatic jumping or accidental collisions with trees or ski towers are responsible for snowboardingrelated pelvic ring fractures, associated or not with sacral fractures. Incidence of pelvic fractures was $2 \%$, and in about $14.5 \%$ patients have occurred axial biomechanical stability problems (21).

Pending of the vertebral lesion and neurological level of injury, immediate and sometimes life-long catastrophic neurological consequences can occur: more or less severe paralysis of the entire body (tetraplegia), or only paralysis of the lower limbs (paraplegia), infra-lesional anesthesia, neurogenic bladder requiring artificial voiding (using indwelling or intermittent urinary probes), neurogenic bowel, respiratory dysfunction, predisposition to pressure ulcers, pulmonary or urinary infections.

Another catastrophic winter-sport event is TBI, the leading cause of death and severe disability in skiing and snowboarding. Approximately 600,000 ski- and snowboarding-related injuries occur in North America each year, and head trauma accounts for $20 \%$ of all injuries (14).

Amateurs ("week-end athletes") aged between 46 to 55 years, and those who never had a professional instruction, or those with rented equipment are predisposed to catastrophic neurological lesions (22). Cerebral trauma was reported in $28 \%$ of all ski injuries, respectively in $15 \%$ (23) up to $33.5 \%$ (24) of all reported snowboarding injuries. 
One must stress that TBI can have fatal outcomes among snowboarders and skiers of all ages, and is the culprit for up to $88 \%$ of all winter sport-related deaths (14). Little research has been conducted on sport-related concussion and injury prevention strategies in competitive sledding sports, like bobsleigh, luge, and skeleton.[Skeleton is a winter sliding sport in which a person rides a small sled, known as a skeleton bobsled (or sleigh), down a frozen track, while lying face down and head-first (25). Prevention strategies are limited, with no possibility of attenuating a catastrophic collision to the head, by interposing the hands. Concussions are a common occurrence in elite sledding sport athletes, affecting $13-18 \%$ of all, and this risk factor was entitled "sled head" (26).

Recreational sledging (tobogganing), very popular in Alpine regions, consists in ascending and sledging down on the same track. Apparently safe and stable, about $9 \%$ participants reported sledging-related injuries to: lower extremities (41\%), arms (22\%), shoulder and back (11\%), or head (10\%) (4).

Overall, $22 \%$ of head injuries can be serious enough to cause clinical signs of concussion (14); acute subdural hematoma represents the most common neurosurgical indication for intervention (27).

Immediate consequences can be devastating, consisting of serious neurological and psychological disorders: different degrees of alteration of the cognitive and executive functions, aphasia, hemiplegia or even tetraplegia, neurogenic bladder, vegetative status and feeding by percutaneous endoscopic gastrostomy (PEG). Unfortunately, most of these severe impairments may persist as life-long disabilities. Due to the violent energy impact, head trauma is the leading cause of mortality after injuries related to skiing and snowboarding (15).

Due to actual objective limitations of therapeutic possibilities of intervention to restore neurological function after TBI and SCI, the best treatment is prevention. Safety helmets are strongly recommended during recreational skiing and snowboarding (14). There is evidence that helmets reduce the risk of head injury by $22-60 \%(5)$.

Helmets are used by most snowboarders $(72 \%)$ and skiers $(74 \%)$, but more than $25 \%$ of all skiers and snowboarders remain at increased risk of serious brain injury, by not wearing a helmet. Females are more "conscious" to wear helmets than males $(80 \%$ vs. $70 \%$ ), and fortunately the highest rates of use were found among 4 - to 12-years-old children (8).
In Netherlands was developed an evidence-based tailored Web-based advice tool (Wintersportklaar) for online intervention, addressed to skiers and snowboarders. It promotes adequate protection equipment, correct information and sustained media education initiatives advocating injury preventive behavioral attitude essential to counteract the "adverse effects" of winter-sports (28).

Severe injuries are more common in snowboarding accidents. Referring to snowboarders: wrist injuries, shoulder soft tissue injuries, ankle injuries, concussions, and clavicle fractures were most frequently seen, whereas in skiers anterior cruciate ligament (ACL) sprain or tear, medial collateral ligament (MCL) sprains, or lateral collateral ligament (LCL) sprains of the knee, lower extremity contusions, and tibia fractures were mostly encountered $(1,19,29)$.

Shoulder injuries were reported in 4 to $11 \%$ of all alpine skiing injuries and in 22 to $41 \%$ of all upperextremity ones (31). During snowboarding, shoulder girdle injuries account for 8 to $16 \%$ of all injuries and for 20 to $34 \%$ of all upper-extremity ones $(1,30)$.

Most common shoulder injuries during skiing and snowboarding were [30]: glenohumeral dislocations (5.5\% of all injuries) (21), rotator cuff strains, acromioclavicular dislocation, and clavicle fractures (4\% of all reported injuries $(9,1)$.

Falls, in addition to pole planting during skiing and aerial maneuvers during snowboarding are the most common causes of shoulder injury (31).

Overall, upper limb injuries in snowboarding have a double frequency, compared to those registered during alpine skiing $(22,29)$. Most common fractures were noticed at the radius $(48 \%)$, clavicle $(11 \%)$, humerus (11\%), and ulna (7-8\%) (32).

Wrist represents the most common location of upper extremity injuries related to snowboarding, accounting for $32 \%$ (33) - up to $44 \%$ of all upper extremity injuries (34]), and fractures accounted for $31 \%$ (33) - up to $78 \%$ of total wrist lesions (34). Snowboarding-related wrist lesions registered between 2010 to 2016 in the emergency departments in the United States included wrist strains/sprains $(25.2 \%)$, contusions $(10.9 \%)$, concussions $(10.0 \%)$, and dislocations (4.0\%) (34).

Usually beginner snowboarders are predisposed to falling and wrist fractures. Snowboarding-related hand injuries accounted for $8.4 \%$ of the total upper extremity lesions (34). 
The natural defense reflex during falling down represents the physiopathological mechanism of the shoulder and/ or wrist injuries. The severity of arm injuries in snowboarding seems to be caused by direct force on the wrist and elbow, which receive the full impact of a fall (29). Analyzing the falling kinematic mechanisms one emphasized that falling backward leads to a wrist injury, whereas a fall forward (toe side) is more predictive of a shoulder injury (19). These aspects explain why upper extremities fractures in snowboarders are three times more common than in skiers, affecting mainly the left upper extremity, with the exception of wrist fractures (35).

Knee is the most common region of the lower extremity injured during skiing, with a mean incidence of 42 injuries per 1,000,000 person-years, and a higher incidence in adults, mainly in males (46 per 1,000,000 person-years) (20).

The anterior cruciate ligament (ACL) is involved in approximately $50 \%$ of all knee serious injuries, due to forced internal rotation and / or valgus loading, in the effort to restore the trajectory of the skis (36).

It is frequently associated with concomitant (other) injuries, such as medial collateral ligament (MCL) sprains, meniscal tears, or tibial plateau fractures (36).

Foot and ankle injuries (ankle fractures and sprains) are most prevalent type of injuries associated with snowboarding, estimated at $15 \%$ of all lesions encountered in this sport (37). Fracture of the lateral process of the talus is relatively unique to snowboarding, and is commonly called the "snowboarder's fracture" (37).

The greatest majority of snowboard-related lesions were encountered in persons who did not have a correct initial instruction from professional staff (93\%) and did not use protective equipment (87\%) (35). Sustained information on specific technical procedures and biomechanical particularities in each winter sport, the correct application of the learned techniques on the slopes, and the encouragement of adequate use of protective equipment are mandatory to avoid possible serious accidents.

This short exposure aims educational approach to stimulate injury preventive behavior among amateur skiers and snowboarders. In a beautiful lyric song Jacques Brel said: "On a beau faire on a beau dire, Qu'un homme averti en vaut deux "/ An informed man is worth two! ").

\section{Conclusion}

In conclusion, referring to winter-sport related catastrophic lesions of the central nervous system, PREVENTION IS CURE !

Disclosures The author has no conflicts of interest to disclose. Abbreviations

ACL, anterior cruciate ligament

LCL, lateral collateral ligament

MCL, medial collateral ligament

SCI, spinal cord injury

TBI, traumatic brain injury

\section{References}

1. Kim S, Endres NK, Johnson RJ, Ettlinger CF, Shealy JE: Snowboarding injuries: Trends over time and comparisons with alpine skiing injuries. Am J Sports Med 2012; 40(4):770-776.

2. Hume PA, Lorimer AV, Griffiths PC, Carlson I, Lamont M., Recreational Snow-Sports Injury Risk Factors and Countermeasures: A Meta-Analysis Review and Haddon Matrix Evaluation. Sports Med. 2015; 45(8):1175-90. doi: 10.1007/s40279-0150334-7.

3. Gaudio RM, Barbieri S, Feltracco P, Spaziani F, Alberti M, Delantone M, et al., Impact of alcohol consumption on winter sports-related injuries. Med Sci Law. $2010 \quad ; 50(3): 122-5 . \quad$ doi: $10.1258 / \mathrm{msl} .2010 .010007$

4. Ruedl G, Pocecco E, Raas C2, Brucker PU3, Greier $\mathrm{K}$, Burtscher M. [Causes of Accidents and Risk Factors Among Adults During Recreational Sledging (Tobogganing): a Retrospective Study]. Sportverletz Sportschaden. 2017; 31(1):45-49. doi: 10.1055/s0043-101044

5. Ackery A, Hagel BE, Provvidenza C, Tator CH, An international review of head and spinal cord injuries in alpine skiing and snowboarding. Inj Prev. 2007 Dec;13(6):368-75.

6. Wolff CS, Cantu RC, Kucera KL, Catastrophic neurologic injuries in sport. Handb Clin Neurol. 2018; 158:25-37. doi: 10.1016/B978-0-444-639547.00004-5.

7. Boden BP, Prior C. Catastrophic spine injuries in sports. Curr Sports Med Rep. 2005; 4(1):45-9.

8. Fenerty L, Thibault-Halman G, Bruce BS, Landry J, Young J, Walling S, Clarke DBHelmets for skiing and snowboarding: who is using them and why. $\mathrm{J}$ Trauma Acute Care Surg. 2013; 74(3):895-900. doi: 10.1097/TA.0b013e31827e19ca.

9. Franz T, Hasler RM, Benneker L, Zimmermann H, Siebenrock KA, Exadaktylos AK: Severe spinal injuries in alpine skiing and snowboarding: A 6-year review of a tertiary trauma centre for the Bernese Alps ski resorts, Switzerland. Br J Sports Med 2008; 42(1):55-58 10.1136/bjsm.2007.038166 
10. Gertzbein SD, Khoury D, Bullington A, St. John TA, Larson AI: Thoracic and lumbar fractures associated with skiing and snowboarding injuries according to the AO Comprehensive Classification. Am J Sports Med 2012; 40(8):1750-1754.

11. Wakahara K, Matsumoto K, Sumi H, Sumi Y, Shimizu K: Traumatic spinal cord injuries from snowboarding. Am J Sports Med 2006;34(10):1670 1674.

12. Tarazi F, Dvorak MF, Wing PC: Spinal injuries in skiers and snowboarders. Am J Sports Med1999; 27(2):177-180.

13. Hubbard ME, Jewell RP, Dumont TM, Rughani AI, Spinal injury patterns among skiers and snowboarders. Neurosurg Focus. 2011;31(5):E8. doi: 10.3171/2011.8.

14. Haider AH, Saleem T, Bilaniuk JW, Barraco RD, Eastern Association for the Surgery of Trauma Injury ControlViolence Prevention Committee. An evidence-based review: efficacy of safety helmets in the reduction of head injuries in recreational skiers and snowboarders. J Trauma Acute Care Surg. 2012; 73(5): 1340-7.

15. Kwiatkowski T. Safety helmets for skiers and snowboarders--efficacy, safety and fitting principles. Review of literature. Przegl Lek. 2015; 72(8):428-31.

16. Benzel EC, Hart BL, Ball PA, Baldwin NG, Orrison WW, Espinosa M, Fractures of the C-2 vertebral body. J Neurosurg. 1994; 81(2):206-12

17. https://www.movementandcreativity.com/blog/podc ast/the-weight-of-your-head

18. Chan CW, Eng JJ, Tator CH, Krassioukov A, Spinal Cord Injury Research Evidence Team. Epidemiology of sport-related spinal cord injuries: A systematic review. J Spinal Cord Med. 2016; 39(3):255-64.

19. Brett D. Owens, ; Christopher Nacca, ; Andrew P. Harris, ; Ross J. Feller, Comprehensive Review of Skiing and Snowboarding Injuries, J Am Acad Orthop Surg. 2018; 26(1):e1-e10.

20. DeFroda SF, Gil JA, Owens BD., Epidemiology of lower extremity injuries presenting to the emergency room in the United States: Snow skiing vs. snowboarding. Injury. 2016; 47(10):2283-2287. doi: 10.1016/j.injury.2016.07.005

21. Ogawa H, Sumi H, Sumi Y, Shimizu K: Pelvic fractures resulting from snowboarding. Am J Sports Med 2010; 38 (3):538-542

22. Patrick E, Cooper JG, Daniels JChanges in Skiing and Snowboarding Injury Epidemiology and Attitudes to Safety in Big Sky, Montana, USA: A Comparison of 2 Cross-sectional Studies in 1996 and 2013. Orthop J Sports Med. 2015, 24; 3(6):2325967115588280. doi: $10.1177 / 2325967115588280$.

23. Levy AS, Smith RH: Neurologic injuries in skiers and snowboarders. Semin Neurol 2000; 20(2):233-245.
24. Sachtleben TR: Snowboarding injuries. Curr Sports Med Rep 2011; 10(6):340-344.

25. https://ro.wikipedia.org/wiki/Scheleton

26. McCradden MD, Cusimano MD. Concussions in Sledding Sports and the Unrecognized "Sled Head": A Systematic Review. Front Neurol. 2018;9:772. $\begin{array}{llll}\text { Published } & 2018 & \text { Sep }\end{array}$ doi:10.3389/fneur.2018.00772

27. Hasler RM, Baschera D, Taugwalder D, Exadaktylos AK, Raabe A: Cohort study on the association between helmet use and traumatic brain injury in snowboarders from a Swiss tertiary trauma center. World Neurosurg 2015; 84(3):805-812.

28. Kemler E, Gouttebarge V., A Tailored Web-based Advice Tool for Skiers and Snowboarders: Protocol for a Randomized Controlled Trial. JMIR Res Protoc. 2018 17; 7(1):e12. doi: 10.2196/resprot.8770.

29. Sasaki K, Takagi M, Kiyoshige $Y$, Ogino $T$ : Snowboarder's wrist: Its severity compared with Alpine skiing. J Trauma 1999; 46(6): 1059-1061

30. McCall D, Safran MR: Injuries about the shoulder in skiing and snowboarding. Br J Sports Med 2009; 43(13):987-992.

31. Kocher MS, Dupré MM, Feagin JA Jr, Shoulder injuries from alpine skiing and snowboarding. Aetiology, treatment and prevention. Sports Med. 1998; 25(3):201-11.

32. Dohjima T, Sumi Y, Ohno T, Sumi H, Shimizu K The dangers of snowboarding: a 9-year prospective comparison of snowboarding and skiing injuries. Acta Orthop Scand. 2001; 72(6):657-60.

33. Seleznev A, Shah NV, Desai R, Le C, Cleary P, Naziri Q, Basu NN, Freeman BJ, Urban WP, Newman JM. Trends of snowboarding-related fractures that presented to emergency departments in the United States, 2010 to 2016.Ann Transl Med. 2018 Jun; 6(11):200. doi: 10.21037/atm.2018.04.32

34. Idzikowski JR, Janes PC, Abbott PJ: Upper extremity snowboarding injuries: Ten-year results from the Colorado snowboard injury survey. Am J Sports Med 2000; 28(6): 825-832.

35. Matsumoto K, Miyamoto K, Sumi H, Sumi Y, Shimizu K, Upper extremity injuries in snowboarding and skiing: a comparative study. Clin J Sport Med. 2002; 12(6):354-9.

36. Hunter RE: Skiing injuries. Am J Sports Med 1999;27(3):381-389

37. Kirkpatrick DP, Hunter RE, Janes PC, et al: The snowboarder's foot and ankle. Am J Sports Med 1998; 26[2]:271-277

38. Munteanu C. - Cell biology considerations in Spinal Cord Injury - Review Balneo Research Journal. 2017; 8(3):136-151 DOI 10.12680/balneo.2017.149 